\title{
Alfonso Reyes en Libra y Sur
}

Rose Corral

El Colegio de México

En México con los Contemporáneos, en Argentina con los integrantes de las revistas Proa y Martín Fierro, y aún antes, en España, siendo él mismo todavía joven, Alfonso Reyes siempre buscó la cercanía de las jóvenes generaciones de escritores. En Madrid, a principios de los años veinte, se interesó por los ultraístas españoles, leyó sus revistas y Guillermo de Torre, quien comentó la obra de Reyes en Cosmópolis, lo consideraba en 1921 "un precursor" de su generación. ${ }^{1}$ Antes de su llegada a la Argentina, Reyes había entablado relaciones epistolares con los directores de la revista Proa y formó parte, en los últimos números de la revista, de un conjunto internacional de "Redactores", al igual que otro mexicano, Xavier Villaurrutia.

Recibido con entusiasmo tanto por Nosotros como por los integrantes de la revista Martín Fierro, no resulta por lo tanto extraño que Alfonso Reyes haya preferido la compañía de los jóvenes escritores a su llegada a Buenos Aires en 1927 y que los proyectos literarios que lleva adelante en el Río de la Plata tengan que ver fundamentalmente con escritores de ese grupo. En ese sentido, el papel desempeñado por Reyes guarda más de una semejanza con el que tuvo Güiraldes en Proa y asimismo con Macedonio Fernández que acompaña a la juventud

\footnotetext{
${ }^{1}$ En una carta a Guillermo de Torre, del 17 de diciembre de 1921, Reyes le escribe: "He leído con verdadero entusiasmo sus benévolas palabras de Cosmópolis [...] Le agradezco a Ud. mucho la apreciación generosa y la situación de precursor que Ud. me concede, grato a la última juventud.” Agradecemos a la doctora Alicia Reyes, directora de la Capilla Alfonsina, la posibilidad de consultar todas las cartas, en su mayoría inéditas, que manejamos a lo largo de este trabajo.
} 
vanguardista desde 1922 cuando aparece la primera Proa. En el único número de la revista Libra, junto con los jóvenes estarán precisamente Reyes y Macedonio. La posterior participación en Sur de Reyes, un miembro activo del "consejo extranjero" de la revista en los años treinta, constituye una etapa distinta, pero no menos sustancial, de la colaboración del mexicano en una revista que se propuso tener una proyección continental. Varios de los ex martinfierristas se integrarán a Sur o serán colaboradores de la misma.

\section{1) $\operatorname{LIBRA}$}

En una extensa carta dirigida a José Ortega y Gasset, del 10 de enero de 1930, cuando está por salir a Brasil, una carta esencial en la que narra sus relaciones y peripecias con los distintos grupos literarios argentinos, dice Reyes: "Un día, sin buscarlo, me vi rodeado y frecuentado por algunos de los jóvenes que considero más escrupulosos y exigentes en materia de letras. [...] Usted comparte conmigo ese sentimiento de verdadera adoración de la juventud. Comprenderá que las visitas de estos muchachos comenzaron a hacerme un bien muy grande". ${ }^{2}$ Aunque Reyes colabora en distintas revistas argentinas del momento (Nosotros, La Vida Literaria, La Literatura Argentina, Don Segundo Sombra, Valoraciones), lo cierto es que los dos proyectos que más le van a entusiasmar y a los que dedicará sus mejores fuerzas tienen que ver con los jóvenes que entonces conforman la vanguardia: se trata de la colección de los Cuadernos del Plata en los que empieza a trabajar junto a Ricardo Molinari y a Jorge Luis Borges, y de la excelente revista Libra, hoy olvidada y muy pocas veces mencionada por la historiografía literaria argentina, ${ }^{3}$ cuyo primer y único número apare-

\footnotetext{
${ }^{2}$ Carta consultada en la Capilla Alfonsina que resulta fundamental para entender los entretelones de la relación de Reyes con los jóvenes escritores. La carta fue publicada en inglés (Bockus 1972). A Valéry Larbaud, Reyes le escribe, en mayo de 1929: "Aquí prefiero juntarme con la gente joven, los de mi edad están algo lejos de mí, espiritualmente" (Larbaud: 58).

${ }^{3}$ En el libro Las revistas literarias argentinas 1898-1967 se registra por lo menos la existencia de Libra. Pero, como se verá, la mención viene acompañada de una descripción escueta e inexacta de la revista: "la poesía de vanguardia recrudece con Libra" (Lafleur 1968).
} 
ce en el invierno austral de 1929. Una revista por otra parte decisiva para entender la creación de Monterrey. Correo literario de Alfonso Reyes, con el cual guarda más de un punto de contacto.

Sólo se ha insistido hasta ahora en la amistad entre Reyes y Borges, que nace precisamente en esos años veinte, y en la influencia que ejercerá Alfonso Reyes sobre el joven escritor argentino. En realidad, basta consultar la correspondencia de Reyes con Ricardo Molinari, Francisco Luis Bernárdez, Ulises Petit de Murat, Eduardo González Lanuza, Oliverio Girondo y Eduardo Mallea, para medir la importancia que tuvo para toda una generación de jóvenes escritores argentinos. ${ }^{4} \mathrm{~A}$ los pocos días de que Reyes dejara Buenos Aires y se trasladara a su nuevo puesto diplomático en Brasil, en abril de 1930, Bernárdez, uno de los directores de Libra, le escribe: "Desde que usted se fue, Buenos Aires es insoportable. No sólo para mí. Para todos los muchachos. Estamos desalentados, aburridos, en el aire. No sé. '¿Para qué escribir —me decía ayer el amigo Molinari-, si ya se fue don Alfonso?' Es cierto. La sola presencia de usted era un estímulo. Ahora, Buenos Aires vuelve a ser el Buenos Aires de siempre. Hostil. Receloso. Duro". ${ }^{5}$

Reyes llega a la Argentina cuando el primer momento de las vanguardias ha pasado: termina la segunda época de la revista Proa un año antes, en 1926, y el periódico Martín Fierro deja de aparecer en noviembre de 1927, muy pocos meses después de que se instalara en Buenos Aires. Desaparecidos los principales órganos de difusión de la obra de los jóvenes, existen varios proyectos (que se frustran o fracasan) para fundar nuevas revistas que respondan a sus inquietudes y que llenen el vacío dejado por aquéllas. Reyes se entera muy pronto de estos proyectos porque los jóvenes se acercan a él para pedirle consejo, alguna colaboración, y sobre todo porque quieren que funde con ellos una nueva revista, a lo cual se resiste por su situación diplomática. En marzo de 1928, Marechal y Bernárdez le escriben a Reyes pidiéndole un texto para una nueva época (la tercera) de Proa, revista que sería dirigida ahora por Borges, Bernárdez y Marechal, y editada por Glei-

\footnotetext{
${ }^{4}$ Esta correspondencia se encuentra en la Capilla Alfonsina de la ciudad de México. A pesar de la cercanía de Reyes con Leopoldo Marechal en esos años, no se conserva en la Capilla Alfonsina ninguna carta cruzada entre ambos.

${ }^{5}$ Carta fechada en Buenos Aires el 9 de abril de 1930 con membrete del periódico El Mundo, Secretario de Dirección. (Capilla Alfonsina).
} 
zer, el editor de buena parte de la juventud literaria del momento. Pero este proyecto, al igual que la anunciada reaparición, por las mismas fechas, de Martín Fierro, no se concretará.

Todo parece indicar que Libra se inscribe en la serie de tentativas que emprenden los jóvenes a finales de la década del veinte con el objeto de fundar un nuevo órgano de difusión para sus obras. Aunque Libra pertenece todavía al periodo vanguardista y la dirigen dos poetas martinfierristas, Francisco Luis Bernárdez y Leopoldo Marechal (Borges formó parte por poco tiempo de la redacción primitiva de la futura revista), rompe en varios sentidos con el patrón acostumbrado de las revistas de vanguardia. Parece tratarse en realidad de una revista de transición entre la primera vanguardia y lo que ha llamado Leopoldo Marechal un "primer llamado al orden", al referirse a su personal trayectoria vanguardista, ${ }^{6}$ un llamado perceptible incluso en el título elegido, un signo del zodíaco que sugiere equilibrio, mesura, armonía, y supone el alejamiento de las confrontaciones o del espíritu de combate de las primeras publicaciones de vanguardia. El papel de Reyes en la fundación de la revista y en la conformación de este primer número fue fundamental. Puede afirmarse que sin Reyes la revista no hubiera aparecido y que "su influencia o su ingenio" (como le escribirá Valéry Larbaud al recibirla) "se reconoce por doquier [...] en la selección de artículos y en la erudición, en la curiosidad y el buen gusto de las notas. [...] Creo firmemente que es la primera vez que la América de lengua española [...] posee una revista literaria de esta calidad y de esta naturaleza" (Larbaud: 67). Aunque Libra constituye un capítulo más de la contribución de Alfonso Reyes a la vida literaria argentina de finales de los años veinte, su papel en la revista dista mucho de ser claro. Sin los datos registrados día a día por Reyes en su Diario y sin muchas de sus cartas, resultaría imposible rastrear la historia de Libra y reconstruir algunos de los eslabones de su corta vida.

Aunque Reyes no acepta comprometerse en la dirección de Libra, colabora intensamente "tras bambalinas" [son sus palabras a Larbaud] con los directores. La revista, que no ostenta ningún manifiesto a la usanza vanguardista ni tampoco un programa inicial, concluye con una

\footnotetext{
6 "Se había dado en mí lo que llamaré un 'primer llamado al orden', que me hacía transitar desde el vanguardismo de Días como flechas a las Odas para el Hombre y la Mujer que preparaba entonces..." (A. Andrés: 30).
} 
extensa sección de notas titulada "Correo literario". Se trata de una sección conformada por noticias literarias, notas eruditas, crítica de arte, incluso notas necrológicas (del hispanista francés Foulché-Delbosc, y de Paul Groussac), una sección debida en buena medida a la pluma de Reyes (aunque sólo firme dos de las notas que escribe: "Proust en América” y "Góngora y América” 7 que tendrá una prolongación en Monterrey, la revista personal que empieza a publicar en Brasil en 1930.

Predomina en Libra una gran diversidad de colaboraciones de distinto signo y época: se ensayan otros derroteros en que lo nuevo (representado aquí sobre todo por los fragmentos en prosa de Bernárdez y de Macedonio Fernández, que publica por primera vez algunos de los prólogos del Museo de la novela de la Eterna) va aparejado con el retorno a la tradición. La cercanía y la colaboración de Reyes con los jóvenes no son ajenos a los cambios de tono y fisonomía que ofrece Libra. Se publican dos poemas de James Joyce (en su versión original junto con la traducción), fragmentos de un epistolario inédito de José Martí, algunos poemas de Marechal (incorporados poco después al libro que publica ese mismo año, Odas para el hombre y la mujer) en los que se advierte un retorno a formas métricas tradicionales, una silva de Gabriel Bocángel, un poeta poco conocido, contemporáneo de Góngora, redescubierto en España por Gerardo Diego y comentado en $\mathrm{Li}$ bra por Ricardo Molinari. Alfonso Reyes encabeza el número con un artículo hoy muy conocido, lleno de ingenio e humor, "Las jitanjáforas" - juegos de palabras desprovistos de sentido, "novedades peligrosas", las llamará con ironía años más tarde—,${ }^{8}$ motivado por la lectura del libro Poemas en menguante del poeta cubano Mariano Brull. El tema seguirá interesando a Reyes y volverá sobre el mismo en varias oportunidades (en la Revista de Avance de Cuba y en su Monterrey), agregando nuevos hallazgos de "jitanjáforas". El artículo de Reyes tuvo una gran resonancia y fue por lo general bien acogido, pero en Buenos Aires, tal vez por estar publicado en una revista conducida por

\footnotetext{
7 Reyes inicia en Monterrey otras secciones parecidas a éstas: "Goethe y América”, "Virgilio y América", el "Boletín alarconiano".

${ }^{8}$ En "Contribución a las jitanjáforas", Reyes recuerda: "Unas notas más a las jitanjáforas que hemos conocido hace tiempo y de que tratamos en La experiencia literaria, con escándalo de sesudos varones, enemigos de estas 'novedades peligrosas' " (Reyes De viva voz 1949).
} 
jóvenes, se interpretó como la señal inequívoca de la conversión de Reyes al vanguardismo. ${ }^{9}$ Gracias a la labor de difusión de Reyes, Libra recibe notas y comentarios en varias revistas del continente y de Europa: en Repertorio Americano de Costa Rica (1929: 202-203), en la Revista de Avance de Cuba (1929), en la revista Contemporáneos de México (1929: 427), en Les Nouvelles Littéraires de Francia, entre otras.

Pero el entusiasmo de Reyes por la revista y por los proyectos con los jóvenes dura poco. En el espacio de unos cuantos meses, pasa en efecto del entusiasmo a la mayor desilusión. En enero de 1930 aflora con nitidez en el Diario su malestar, que atribuye principalmente al ambiente literario porteño (la "politiquería” de los grupos literarios), un ambiente hosco, falto de cordialidad: una queja que va sin duda más allá de Libra. Decide desligarse de todo y de todos. Es forzoso reconocer que en las relaciones de Reyes con los jóvenes argentinos hay dos dimensiones: una pública (la historia oficial, en suma), que pone en un primer plano los proyectos en común y los logros, y una dimensión privada, que no trascenderá, en la que afloran los conflictos y las diferencias. Reyes no comparte en particular sus puntos de vista "en materia de nacionalismo y americanismo", ${ }^{10}$ un asunto que ya había provocado algunas fricciones entre el grupo de los Contemporáneos y los nuevos poetas argentinos. ${ }^{11} \mathrm{La}$ nacionalidad es una suerte de fatalidad, no necesita exhibirse, había escrito Torres Bodet en un ensayo dedicado al "paisaje de México" en la poesía (1928), y en otro ensayo dedicado a los poetas argentinos había criticado el "falso criollismo" de Borges. Se explica entonces el recelo de Reyes y de los Contemporáneos con esta veta nacionalista de la literatura rioplatense de vanguardia, ya que era también en México un frente de batalla del grupo. Poco después, en 1932, empezaría el bien conocido ataque de

\footnotetext{
${ }^{9}$ Ortega y Gasset es, de nuevo, el interlocutor con quien Reyes es más explícito: "Yo publiqué en Libra una humorada llamada 'Las jitanjáforas', que en nada difiere de mi habitual humorismo, y que en tiempos más conscientes de la alegría literaria, se hubiera tomado por lo que es: un juego literario. ¿Creerá usted que no faltó por ahí alguien que me dijera que había yo escandalizado a muchas personas? Y hasta otro que me saliera con aquello de pasarse [a los otros, o sea a los jóvenes]? 'Ya veo que se ha pasado usted a la gente joven. Hace usted bien, porque ésos son el porvenir' " (Capilla Alfonsina).

${ }^{10}$ Remitimos de nuevo a la carta a Ortega y Gasset.

11 Para mayor información véase Corral 2001: 517-526.
} 
los "nacionalistas" a los Contemporáneos en el que también se verá envuelto Reyes. ${ }^{12}$

La interrupción de la revista se pudo deber a varios factores: la falta de financiamiento, el viaje de Leopoldo Marechal a Francia en diciembre de 1929, sin duda también el retiro del apoyo de Reyes. En la carta a Bernárdez en que le anuncia que se desliga de su compromiso con Libra, Reyes le envía el material que tiene en su poder (algo de Molinari y de Marasso) y agrega: "Perdóneme que no me sienta con fuerzas para hacer por el segundo número de Libra lo que hice por el primero. Pero la cosa va en serio. Tengo que concentrarme en ciertos deberes apremiantes". Si Reyes aceptó finalmente colaborar con los jóvenes fue porque hubo un acuerdo sobre el tipo de revista que se proponían hacer, una revista menos beligerante que Martín Fierro, que dialogara no sólo con la literatura nacional y la continental sino también con la tradición literaria española. Tal vez no fue fácil lograr el equilibrio deseado por Reyes, en particular el abandono de las posturas nacionalistas, pero su consejo a los jóvenes — "hacer una labor de depuración”, "asear su propia casa" - se impuso finalmente en el único número de Libra. ${ }^{13}$

\section{2) $S_{U R}$}

La apertura buscada por Reyes para superar los nacionalismos estrechos, la noción de una patria ensanchada, continental, y la importancia de la mirada del otro para la comprensión de lo propio son ideas rectoras de la revista Sur en sus primeros años de vida, ideas con las cuales el escritor mexicano se sentirá inmediatamente afín. Reyes estuvo estrechamente vinculado al nacimiento de la revista Sur, cuando todavía era un

\footnotetext{
12 La única polémica pública de Reyes en torno al asunto del nacionalismo la tendrá con Ramón Doll, un joven crítico que rebate sus argumentos (y los de Ortega con quien lo asocia) en torno "a la nación argentina", su percepción del país como una lucha entre patricios y plebeyos (1959: 36-41).

${ }^{13}$ Carta del 10 de enero de 1930. Capilla Alfonsina. En forma más directa, ese mismo día, le escribe a Ortega y Gasset: "trabajé mucho para el primer número de invierno, acaso el único que llegue a salir, puesto que en cuanto los dejé solos, no han sido capaces de sacar el de primavera ni el de verano" (Carta ya citada a Ortega y Gasset).
} 
proyecto. Su participación activa se limita a la primera década de vida de la revista, antes del regreso definitivo del escritor a México. Posteriormente, Reyes sólo se hará presente en los números conmemorativos. Su última colaboración, "Trayectoria de la religión griega", aparece en 1951, en el número que festeja los veinte años de la revista.

Un año antes de que saliera Sur, Reyes anota en su Diario: "Todo este tiempo, luchando para aclarar a Victoria sus propias indecisiones sobre esta insulsa idea de hacer una revista interamericana dirigida por Waldo Frank y por ella, y con la asociación de Glusberg” (295). El proyecto inicial de revista "interamericana", cuyo título tentativo es Nuestra América, no convence a Reyes, quien sospecha, como efectivamente sucedió, que la asociación de Victoria Ocampo con Samuel Glusberg (el editor de la revista y editorial Babel) no funcionará. ${ }^{14} \mathrm{Re}-$ yes, que ya conoce bien el ambiente literario porteño, las ásperas divisiones entre los distintos grupos, se percata de la ingenuidad o inocencia de Frank. En una carta dirigida a Genaro Estrada, dice Reyes: “¡Cosas de Waldo Frank que está empeñado, ya casi con afectación, en que todos los hombres son muy buenos y son sus hermanos! ¡El pobre no conoció el ambiente!" (Zaïtzeff: 254). Como es bien sabido, Frank seguirá insistiendo hasta convencer a Ocampo de la necesidad de crear una revista americana, una revista que ayude a tender puentes entre las dos Américas y con Europa. En la "Carta a Waldo Frank" que encabeza el primer número, Victoria Ocampo sintetiza el programa de la revista: Sur es (y será) la revista "de los que han venido a América, de los que piensan en América y de los que son de América. De los que tienen la voluntad de comprendernos, y que nos ayudan tanto a comprendernos a nosotros mismos" (1931: 16). Reyes comparte varias de las inquietudes iniciales de Sur, principalmente la reflexión sobre el "complejo americano", como lo llama en uno de los primeros números de su Monterrey, pero sin adherirse al desmedido optimismo de Frank o al de Ocampo. Sus variadas reflexiones sobre la cuestión americana en su "Correo literario", en las secciones "Aseo de

\footnotetext{
${ }^{14}$ No deja de ser sorprendente que todavía en junio de 1930, poco antes del regreso de Victoria Ocampo de los Estados Unidos, Samuel Glusberg le escriba a Reyes: "Espero el regreso de Victoria para realizar el proyecto de revista americana que usted conoce y, naturalmente, cuento con usted" (Carta del 10 de junio de 1930. Capilla Alfonsina).
} 
América", "Guardias de la pluma" o "Los ojos de Europa", son paralelas a las que se llevan a cabo en Sur. ${ }^{15}$ Entusiasmado por el primer número de Sur que acaba de recibir, Reyes le escribe a Victoria Ocampo: "Sur va a ser como nuestra patria. Ya verá qué activo ciudadano resulto yo. Preparo colaboraciones en verso y prosa, y me permitiré enviarle cuantas sugestiones se me ocurran. La vida tiene ahora más peso” (Perea: 19).

Como se desprende de la correspondencia inédita entre Reyes, Eduardo Mallea, Guillermo de Torre, el secretario de la revista, y María Rosa Oliver, los miembros de Sur (no sólo Ocampo) consultan de manera seguida a Reyes: le piden colaboraciones, consejos y apoyo. La presencia de México es importante en los primeros números; el 4, en particular, que Guillermo de Torre llama en sus cartas a Reyes "el número mexicano", por la profusión de ilustraciones sobre México: pinturas murales de Roberto Montenegro (antes ya se habían publicado algunas de Diego Rivera), fotos de Manuel Álvarez Bravo y de la película de Eisenstein sobre México. La correspondencia revela también que Reyes prosigue para Sur, desde Brasil ahora, el papel de intermediario entre México y el Río de la Plata que ya había desempeñado en sus años porteños entre Contemporáneos y la juventud argentina. Sur se propone integrar, desde un principio, a los "muchachos de México", como dice Mallea, solicitando textos de "Torres Bodet, Villaurrutia, Owen — todo ese bello núcleo, agrega, que bien comenzaría a representar a una juventud americana en Europa-". ${ }^{16}$ Se consulta a Reyes, al igual que a Ortega y Gasset, para buscar un nombre menos trillado que el primitivo "Nuestra América", se barajan varios nombres en cartas cruzadas entre Ma-

15 No hay que olvidar que el año de 1929 - en 1928 Ortega y Gasset estuvo también en la Argentina - fue el año en que ilustres viajeros extranjeros visitaron el país; primero, en junio, el conde de Keyserling, invitado por Victoria Ocampo, y poco después Waldo Frank. Los libros que dedicaron al país y a América tuvieron una honda repercusión. Poco después de la visita de Waldo Frank a Argentina, el 30 de noviembre de 1929, Reyes, más escéptico en torno a estos temas, escribe en su Diario: "El otro día pensé cómo podía empezar mi soñada Depuración de América con un capítulo que sería: 'Examen de profecías'. Todo eso de 'la hora de América', y las ideas de Vasconcelos y Frank que flotan en el ambiente de nuestra época, y de la decadencia de esto y el nacimiento de lo otro. Y si se puede hablar — en el estado actual de la intercomunicación humana y de nivelación geográfica- de la posibilidad de una 'cultura americana' futura diferente y específica, que siempre he creído absurdo" (1969: 294).

${ }^{16}$ Carta de Eduardo Mallea del 10 de octubre de 1930 (Capilla Alfonsina). 
llea, de Torre y Reyes (“Terranova”, “América y Compañía”, “Américas", "Rutas", "Rumbos”, "Señales”), y cuando finalmente Victoria Ocampo se decide por Sur, aconsejada por el filósofo español, Eduardo Mallea le explica a Reyes el sentido del título elegido, adelantándose a posibles objeciones y ofreciendo al mismo tiempo su lectura particular de la palabra "Sur", que anticipa sus propias ideas sobre el ser nacional: "Este título no importa, sin embargo, una limitación, sólo determina el punto donde han de confluir las meditaciones de todos los colaboradores, tanto del sur como del norte, del este o el oeste. Esto de Sur tiene también un sentido de 'revelación' (de revelación de valores y problemas), una voluntad de hacer nacer las plantas en una suerte de tierra culturalmente maldita". ${ }^{17}$

"Un paso de América", una nota de Reyes publicada originalmente en su revista Monterrey, de la que se "apropia" literalmente Sur para el primer número, es un texto que anticipa sus "Notas sobre la inteligencia americana”, publicado también en Sur, en 1936. El artículo de Reyes que la revista decide publicar sin siquiera avisarle — se entera al recibir el primer número- ${ }^{18}$ tiene sin duda una importancia estratégica para Sur: después de enunciar una serie de "fatalidades concéntricas" que aquejaban a los americanos de la generación anterior a la suya (ser hombre — como en Calderón-, ser modernos, americanos, latinos, hispanoamericanos, pertenecer a la zona indígena del continente y vivir en la vecindad peligrosa de una nación pletórica), Reyes hace la crítica de las miradas europeas que todavía buscan en lo americano el exotismo o el color local, para finalmente terminar con una nota optimista y apuntar "la mayoría de edad" alcanzada por América y la entrada del continente al mundo universal de la cultura. La nota de Reyes será recordada por Victoria Ocampo y Guillermo de Torre varios años después porque en la misma es posible vislumbrar lo que será el programa de la revista en esos primeros años de vida. Sur, agregará Ocampo, ha contribuido "a abrir de par en par las ventanas" (como lo sugería Reyes en esta primera nota), para hacer frente a lo que llamaba las "fatalidades concéntricas" (Ayerza: 295-296).

\footnotetext{
${ }^{17}$ Carta de Mallea, sin fecha, aunque sin duda de noviembre o diciembre de 1930 (Capilla Alfonsina).

18 "iLlegó Sur! [...] La reproducción de mi artículo de Monterrey me ha sido gratísima sorpresa" (Perea: 19).
} 
Otro punto de contacto o coincidencia interesante entre Sur y Monterrey, la revista personal de Reyes, es la importancia que atribuyen a la percepción de América por parte de los viajeros extranjeros, una mirada que debe ayudar en la búsqueda "de una nueva expresión, un nuevo sentir y un nuevo hacer, que correspondan mejor a las realidades de la vida en el Nuevo Mundo" (Monterrey, 5 de abril de 1931: 1). Es en ese sentido que Reyes inaugura la sección "Los ojos de Europa", en la que se propone meditar sobre los testimonios de los europeos que "tratan a América de igual a igual" y que "vienen a ser como un útil bizqueo, para mejor enfocar un objeto que hasta entonces sólo vimos de lejos y que de repente, se nos acerca". En el mismo artículo, Reyes comenta el "México de Morand" y alude también, de pasada, a D. H. Lawrence: "El recién desaparecido Lawrence tuvo tiempo para demostrar que gustaba como buen catador de las mañanas de México (Mornings in México)". ${ }^{19}$ Éste será también un tópico esencial en Sur (el que está sin duda en el origen del ensayo sobre el "ser nacional" que singulariza esta década), que dio demasiado espacio al testimonio a veces discutible de algunos viajeros, como en el caso de Keyserling. Pero frente a la cerrazón y al nacionalismo anteriores de parte de la vanguardia argentina, debe destacarse ahora la apertura de Sur y la de Reyes, receptivos ambos a las críticas. En efecto, tanto Victoria Ocampo como Reyes saludaron los ensayos de Ortega y Gasset sobre la Argentina que habían generado tanta polémica entre los jóvenes. ${ }^{20}$ En este contexto, no resulta tampoco extraña la insistencia con la que María Rosa Oliver y Victoria Ocampo le solicitaron a Reyes, sin éxito, su

${ }^{19}$ Sobre la mirada extranjera dice también Reyes: "Claro que el ser extranjero da una desviación a la perspectiva, pero esto no falsea necesariamente la presentación de la realidad, antes sirve para mejor conocerla y abarcarla" (Monterrey, 4 de abril de 1931: 1-2).

${ }^{20}$ En la carta ya citada a Ortega y Gasset, Reyes se refiere a la reacción airada (y nacionalista) de sus jóvenes amigos de vanguardia (Borges, Bernárdez, Marechal) frente a los escritos de aquél sobre la Argentina. Por el contrario, y por las mismas fechas, Victoria Ocampo coincide con Reyes: "Ni los ataques, ni los elogios en sí, pueden sernos provechosos. [...] Necesitamos que nos traigan claridad. Venga de donde venga, de nosotros mismos o del vecino. [...] Yo quisiera agradecerle públicamente a Ortega el placer que me causó leer en su libro las páginas que nos conciernen. Quiero agradecerle tanta inteligencia puesta al servicio de tanta sinceridad" (Ocampo: 116-117). 
opinión sobre el México de D. H. Lawrence, uno de los primeros autores traducidos (la novela Canguro) por la editorial Sur. ${ }^{21}$ Lo más probable, como se desprende de su Diario, es que Reyes no quiso polemizar abiertamente con la visión de Lawrence que no acababa de convencerle: "Comencé por elogiarlo un poco a crédito, bajo la fe de Pedro Henríquez Ureña. Me temo que, cuando me ponga a ello, mi opinión no sea tan optimista”. ${ }^{22}$

Si en Sur el papel de Reyes en esos primeros años de la revista parece haber sido principalmente de contención o moderación, en particular frente a los excesos del americanismo, en la revista Libra se da un primer ensayo, estimulado y guiado por Alfonso Reyes, por abandonar las posturas extremas de la vanguardia martinfierrista, un intento por ampliar los horizontes de los jóvenes que les permitiera dialogar con otras tradiciones.

\section{BiBLIOGRAFÍA}

Andrés, A. Palabras con Leopoldo Marechal. Buenos Aires: Carlos Pérez, 1968.

Ayerza de Castilho, laura y Odile Felgire. "Lettre de Victoria Ocampo sur la création de Sur", en Victoria Ocampo. París: Criterion, 1991. 295-296.

Bockus Aponte, Bárbara. Alfonso Reyes and Spain. Texas: University of Texas Press, 1972.

Contemporáneos. 19 (diciembre de 1929). 427.

Corral, Rose. "El grupo de Martín Fierro y los poetas de Contemporáneos", en Caravelle. Cahiers du monde hispanique et lus-bresilien. Toulouse-Le Mirail: Presses Universitaires du Mirail. 76-77 (2001). 517-526.

Larbaud, Valéry / Alfonso Reyes. Correspondance 1923-1952. Introducción y notas de Paulette Patout. París: Klincksieck, 1972.

\footnotetext{
${ }^{21}$ En enero de 1932, María Rosa Oliver formula de nuevo el pedido enviándole a Reyes un libro de Lawrence: "Le mando con esta carta Saint Mawr, para que fije de una vez por todas y para todos cuál es lo verdadero en el México de Lawrence" (Capilla Alfonsina).

22 Diario inédito de Reyes consultado en la Capilla Alfonsina. Esta anotación aparece con la mención "Río, 24 de septiembre de 1931".
} 
Lafleur Provenzano y Alonso. Las revistas literarias argentinas, 1898-1967. Buenos Aires: Cedal, 1968.

Ocampo, Victoria. "Quiromancia de la Pampa", en Testimonios. Primera serie 1920-1934. Buenos Aires: Sur, 1981. 116-117.

Perea, Héctor (ed.). Alfonso Reyes / Victoria Ocampo. Cartas echadas. (Correspondencia 1927-1959). México: Universidad Autónoma Metropolitana, 1983. 19.

Repertorio americano. Costa Rica: Año XI. 467, 5 de octubre de 1929.

Revista de Avance 1929. Cuba: La Habana, diciembre de 1929.

Revistas literarias mexicanas modernas. Antena. 1924. Monterrey, 1930-1931. Examen 1932. Número 1933-1935. México: Fondo de Cultura Económica, 1980 [Ed. facsimilar].

—. De viva voz. México: Tezontle, 1949.

. Obras completas IX. México: Fondo de Cultura Económica, 1959. 3641.

—. Diario 1911-1930. Prólogo de Alicia Reyes y nota de Alfonso Reyes Mota. México: Universidad de Guanajuato, 1969.

Sur, núm. 1, verano de 1931.

Torres Bodet, Jaime. "El paisaje en México", en Contemporáneos: notas de crítica. México: Herrero, 1928.

Zaïtzeff, Serge (ed.). Con leal franqueza. Correspondencia entre Alfonso Reyes y Genaro Estrada. 2. México: El Colegio Nacional, 1993. 
